\title{
Estimulación temprana con canciones infantiles para centros educativos
}

\author{
Carmen Andrés Jiménez \\ Universidad Estatal a Distancia (UNED), 474-2050 Mercedes de Montes de Oca, San José-Costa Rica; \\ candres@uned.ac.cr, shamiltongarcia@gmail.com
}

Recibido 05-V-2018 • Corregido 17-VII-2018 • Aceptado 14-XI-2018

\begin{abstract}
Children songs as early stimulation in schools". Introduction: early musical stimulation is a useful tool that improves development in linguistics, and in motor, cognitive and social skills in small children. The process is complex and specific and can be done by ear or by writing a score. Objective: to develop a method with children's songs to stimulate from babies to children of three years that can be used from individuals to public and private institutions such as care networks and day care centers. Methods: based on my own family experience, I recommend five stages: preliminary (listening to classical music inside the womb), stage one (music that shows love for the children), stage two (music to develop gross motor skills), stage three (music for fun and social skills) and stage four (music to develop cognitive skills). Result: music as an early stimulation tool reinforces the love bond between parents and child and could promote the bond between teachers and children. Conclusion: my impression is that the method had positive effects on my children's sleep, gross motor skills, social adeptness, cognitive development and linguistics.
\end{abstract}

Key words: children music, early stimulation, cognitive development, social skills, gross motor, linguistics.
RESUMEN: Introducción: la estimulación musical temprana es una herramienta útil que mejora el desarrollo en la lingüística y en las habilidades motoras, cognitivas y sociales de niños pequeños. El proceso es complejo y específico, y se puede hacer de oído o escribiendo una puntuación. Objetivo: desarrollar un método con canciones infantiles para estimular desde bebés hasta niños de 3 años que se pueda utilizar desde personas particulares a instituciones públicas y privadas como redes de cuido y guarderías. Métodos: basándome en mi propia experiencia familiar, recomiendo cinco etapas: preliminar (escuchar música clásica dentro del útero), etapa uno (música que muestra amor por los niños), etapa dos (música para desarrollar habilidades motoras gruesas), etapa tres (música para la diversión y las habilidades sociales) y la etapa cuatro (música para desarrollar habilidades cognitivas). Resultado: la música como una herramienta de estimulación temprana refuerza el vínculo entre padres e hijos y podría promover el vínculo entre maestros y estudiantes. Conclusión: mi impresión es que el método tuvo efectos positivos en el sueño de mis hijos, las habilidades motoras gruesas, la habilidad social, el desarrollo cognitivo y la lingüística.

Palabras clave: música infantil, estimulación temprana, desarrollo cognitivo, habilidades sociales, motora gruesa, lingüística.
La estimulación temprana es una herramienta que desarrolla y potencia las funciones del cerebro desde el vientre materno, para potenciar las funciones de los aspectos cognitivo, lingüístico, motriz y social (Fajardo, Avilés, \& Matamoros, 2018). Estas son las cuatro áreas que el método de estimulación temprana diseñado en esta sistematización de experiencia, debe contemplar.

El uso de la música en la estimulación temprana es importante para el desarrollo en los niños. Benítez, Díaz y Romina (2017) indican sobre la existencia de evidencias que establecen que la educación musical influye positivamente en el desarrollo cognitivo del niño, así como sus destrezas psicomotrices, emocionales y sociales.
Narváez (2018) indica que las canciones infantiles y el desarrollo de la inteligencia lingüística están relacionadas, dado que fortalecen la autonomía, autorregulación y autoconocimiento. Asimismo, el Licenciado en piano Fernando Andrés, con más de cuarenta años de experiencia en la enseñanza de niños, la música crea en el niño una sensibilidad mucho mayor hacia las personas, sus problemas, sus necesidades y sus diferencias, generando adultos más empáticos, solidarios y responsables.

Otro aspecto también relacionado con el éxito de la estimulación temprana es el apoyo que los niños deben recibir desde su casa. Estudios realizados por expertos indican que existe relación entre el desarrollo del sistema 
sensorial (que incluye la audición) y el desarrollo de la expresión oral (Arcos-Carhuamaca \& Uscuchagua-Cornelio, 2017), de manera tal que la estimulación temprana debe empezar en casa y no dejarla solamente para las entidades que la imparten.

Flores (2013) indica que la estimulación temprana a través de diferentes métodos, entre ellos la musicoterapia, genera un incremento significativo del desarrollo psicomotor en comparación con niños que no reciben ningún tipo de estimulación.

Aguilar-Cordero et al. (2012) indican que la estimulación musical en el embarazo es beneficiosa, dado que encontraron que los niños que recibían este tipo de beneficio, tenían un mejor apgar y mayor peso.

Otra teoría interesante respecto a la estimulación temprana a través de la música, la aporta Frega (2005), donde indica que "generar confianza en sí mismo, para que el niño ose, se anime, lo intente; es vital para el desarrollo de la expresión" (p. 18).

El objetivo de esta sistematización de experiencia es desarrollar un método con canciones infantiles para estimular desde bebés hasta niños de 3 años, que se pueda utilizar desde personas particulares a instituciones públicas y privadas como redes de cuido y guarderías.

\section{MATERIALES Y MÉTODOS}

Procedimiento para componer cada canción infantil: la composición de este conjunto de canciones infantiles se llevó a cabo en un periodo total de cinco años, durante los cuales se compusieron de acuerdo con diferentes circunstancias que giraban alrededor de los hijos de la autora. Se expondrá la manera en la que se compuso cada canción musicalmente hablando, de manera que pueda servir de guía para quien quiera también escribir canciones que pueden ser útiles para enseñar diferentes temas, no sólo académicos sino también de disciplina, comportamiento, buena alimentación, entre otros.

Creación de un método de enseñanza musical para recién nacidos hasta niños de 3 años: se ideó una metodología a partir de la cual los padres de familia, encargados de guarderías, de redes de cuido o centros privados de estimulación temprana puedan utilizar para sus lecciones, para romper la rutina y utilizar como un complemento que estimule a los pequeños a través de este instrumento tan maravilloso que es la música.

Es importante que este método contemple, como lo dice la teoría, los cuatro elementos fundamentales de la estimulación temprana, donde se debe desarrollar los aspectos: cognitivo, motriz, lingüístico y social.

Descripción de cada canción y la manera en la que se puede utilizar: se describió la esencia de cada canción, la razón por la que fue compuesta y el fin con el que podría utilizarse en una clase de estimulación temprana o en la casa. Se describe la manera en la que se probó que fue solamente con los hijos de la autora y algunos otros niños. Esta es una prueba piloto que se puede ampliar en un siguiente estudio.

Ética, conflicto de intereses y declaración de financiamiento: la autora declara haber cumplido con todos los requisitos éticos y legales pertinentes, tanto durante el estudio como en el manuscrito; que el estudio está basado en la experiencia personal con sus hijos, y que el financiamiento para su desarrollo fue propio. Asimismo, está de acuerdo con la versión editada final del documento. El respectivo documento legal firmado se encuentra en los archivos de la revista.

\section{RESULTADOS}

Procedimiento para componer cada canción infantil: la creación de una canción es algo muy delicado, como un cristal y si no se logra moldear a tiempo, se esfuma como un sueño y no se logra recuperar, hasta que la inspiración vuelva a llegar.

Cabe mencionar que este método es basado en la experiencia de la autora y su conocimiento musical y no pretende sustituir teorías ya existentes, sino aportar una idea original que ha funcionado, para el conocimiento general.

Cada una de las canciones que están en esta sistematización de experiencia, fue creada con base en alguna inspiración, algún momento importante de la vida que muestra el camino a seguir para que una canción nazca.

No es suficiente; sin embargo, vivir un momento así, sino que; por el contrario, se necesita también tener el conocimiento musical para poder armar el rompecabezas de todas esas emociones juntas que al final pueden convertirse en canción.

En el cuadro 1 se dan algunos pasos que pueden ser de ayuda para quien quiera profundizar en este tema y no existe una sola manera de componer una canción infantil, sino que depende de cómo inicie la idea y de si la persona puede o no escribir una partitura, como se verá a continuación: 
CUADRO 1

Metodología original para componer una canción infantil

\begin{tabular}{ll}
\multicolumn{1}{c}{ Sección } & \multicolumn{1}{c}{$\begin{array}{c}\text { Alternativa con grabadora } \\
\text { Tema principal }\end{array}$} \\
$\begin{array}{l}\text { Grabar la melodía que se nos ocurrió para } \\
\text { posteriormente trabajar con la misma. Este es el tema de } \\
\text { la canción que termina en una nota que expresa un signo } \\
\text { de pregunta. }\end{array}$ \\
Desenlace \\
$\begin{array}{l}\text { Grabar el mismo tema de la canción, pero agregándole } \\
\text { un desenlace; es decir, la nota en la que termine no debe } \\
\text { dejar duda, sino, resolver la pregunta que se hizo en el } \\
\text { tema principal. }\end{array}$
\end{tabular}

Escoger la tonalidad en la que se quiere escribir la canción (normalmente en tonalidades mayores porque son canciones alegres).

Escribir el tema de la canción, que consta máximo de tres compases y el último compás termina con una quinta o una cuarta.

Repetir el tema principal hasta llegar a la quinta o cuarta. Finalizar la canción con el acorde dominante.

\begin{abstract}
Creación de un método de enseñanza musical para recién nacidos hasta niños de 3 años: el método que se propone puede utilizarse como un complemento al resto de las estrategias que existen de estimulación temprana, no se pretende que sea la única herramienta con la que se pueda realizar la estimulación; por el contrario, es una opción para romper la rutina o realizar cambios a lo que ya se tiene establecido en cada instancia educativa o en la casa.
\end{abstract}

Este método no pretende sustituir los métodos oficiales de estimulación temprana diseñados por expertos, sino es un aporte que se puede considerar como una opción que complemente lo que ya se utiliza (Cuadro 2).

Descripción de cada canción y la manera en la que se puede utilizar: a continuación, se presenta cada una de las canciones del método musical de estimulación temprana, en orden de dificultad para el bebé, de

CUADRO 2

Método musical de estimulación temprana basado en canciones infantiles

\begin{tabular}{|c|c|c|c|c|}
\hline Etapa & Nombre & Descripción & Ejercicios & $\begin{array}{c}\text { Aspecto que } \\
\text { desarrolla }\end{array}$ \\
\hline Preliminar & $\begin{array}{l}\text { Ubicación } \\
\text { musical }\end{array}$ & $\begin{array}{l}\text { El niño escucha música clásica, } \\
\text { Baby Einstein o alguna música para } \\
\text { relajarse }\end{array}$ & $\begin{array}{l}\text { Esto se debe realizar desde el vientre materno, } \\
\text { con audífonos que no estén muy altos pero } \\
\text { tampoco muy bajos. Se deben escuchar al } \\
\text { menos } 20 \text { minutos por día. }\end{array}$ & $\begin{array}{l}\text { Lingüístico, } \\
\text { cognitivo }\end{array}$ \\
\hline Primer nivel & $\begin{array}{l}\text { Escuchar } \\
\text { las primeras } \\
\text { canciones }\end{array}$ & $\begin{array}{l}\text { Se debe escoger una canción que } \\
\text { exprese puro amor (Te amo, mi } \\
\text { amor o Good morning/Good night) }\end{array}$ & $\begin{array}{l}\text { Se le canta al bebé desde que está en el } \\
\text { vientre materno, todos los días, en todos los } \\
\text { momentos del día, para fortalecer el nexo } \\
\text { entre madre e hijo. También puede cantarla el } \\
\text { padre, ajustándole el tono a las canciones, en } \\
\text { las noches antes de dormir o en las mañanas } \\
\text { mientras lo baña. }\end{array}$ & $\begin{array}{l}\text { Lingüístico, } \\
\text { cognitivo, social }\end{array}$ \\
\hline Segundo nivel & $\begin{array}{l}\text { Escuchar las } \\
\text { canciones } \\
\text { y hacer } \\
\text { dinámicas con } \\
\text { el cuerpo }\end{array}$ & $\begin{array}{l}\text { Se utilizan las canciones que } \\
\text { permiten hacer dinámicas como } \\
\text { "Bollito de pan"y "Tortillitas", de } \\
\text { manera que no sólo se estimula } \\
\text { el oído, sino también la motora } \\
\text { gruesa y la vista }\end{array}$ & $\begin{array}{l}\text { Acostado en la cama, con una colchoneta, el } \\
\text { bebé escucha "Bollito de pan"y se le da vueltas } \\
\text { como si se tuviera un rodillo y se estuviera } \\
\text { amasando pan. } \\
\text { Al cantar"Tortillitas", se le muestra al bebé } \\
\text { como hacer las palmaditas hasta que él lo va } \\
\text { logrando, primero con ayuda y después solo, } \\
\text { con los meses. }\end{array}$ & $\begin{array}{l}\text { Lingüístico, } \\
\text { cognitivo, motor }\end{array}$ \\
\hline Tercer nivel & $\begin{array}{l}\text { Cantar para } \\
\text { divertirse }\end{array}$ & $\begin{array}{l}\text { El divertirse es parte vital para } \\
\text { la salud mental y a los bebés les } \\
\text { encanta. Para eso es la canción } \\
\text { "Mamón chino", para generar } \\
\text { felicidad y empezar a socializar, que } \\
\text { es parte importante del desarrollo. }\end{array}$ & $\begin{array}{l}\text { Escuchar y cantar la canción "Mamón chino", } \\
\text { aplaudiendo y riendo de lo absurda y dulce } \\
\text { que es la canción a la vez. Se debe lograr que } \\
\text { el bebé se sienta feliz con sus padres o sus } \\
\text { cuidadores a través de esta canción. }\end{array}$ & $\begin{array}{l}\text { Lingüístico, } \\
\text { cognitivo, social, } \\
\text { motor }\end{array}$ \\
\hline Cuarto nivel & Aprender & $\begin{array}{l}\text { No se pretende que el bebé } \\
\text { aprenda una canción, pero sí } \\
\text { aprenderá inglés o las vocales. Con } \\
\text { la canción "A E I O U”, se logrará } \\
\text { captar la atención en el área } \\
\text { cognitiva académica del niño. }\end{array}$ & $\begin{array}{l}\text { Escuchar y cantar "A E I O U”, dando énfasis en } \\
\text { que es para aprender. La sección en inglés se } \\
\text { debe introducir después de que la canción } \\
\text { ya resulta familiar para el pequeño y que la } \\
\text { disfruta. De esta manera, tolerará más que se le } \\
\text { cante en otro idioma. }\end{array}$ & $\begin{array}{l}\text { Lingüístico, } \\
\text { cognitivo. }\end{array}$ \\
\hline
\end{tabular}


manera que va desde el nivel preliminar hasta llegar al cuarto nivel; todas las canciones están protegidas por ACAM, Costa Rica:

La primera es "Te amo, mi amor" (Fig. 1) compuesta para mi segundo hijo la semana en que nació. Esta canción es muy tierna y tiene un significado muy especial, es ese sentimiento único que nos inspira un hijo y el amor infinito de madre hacia hijo.

La canción tiene unos guiones en el espacio donde iría el nombre de mi hijo, por lo que cada mamá, cada maestra, cada especialista puede sustituir el nombre de cada niño con el que trabaje en esos espacios. La canción es para demostrar seguridad, amor y que el lazo que los une es irrompible.

La segunda canción del método se llama "Good morning/Good night" (Fig. 2) es, como lo dice su nombre, para iniciar el día o para irse a la cama. Es bien sabido que un buen despertar es indispensable para los bebés, así como poder irse a la cama de manera tranquila para ir regulando el sueño, que en algunos casos es muy complicado.

Esta canción se la compuse a mi hijo mayor cuando estaba en el vientre, es la que tiene mayor significado para mí porque el sentimiento que expresa es precisamente
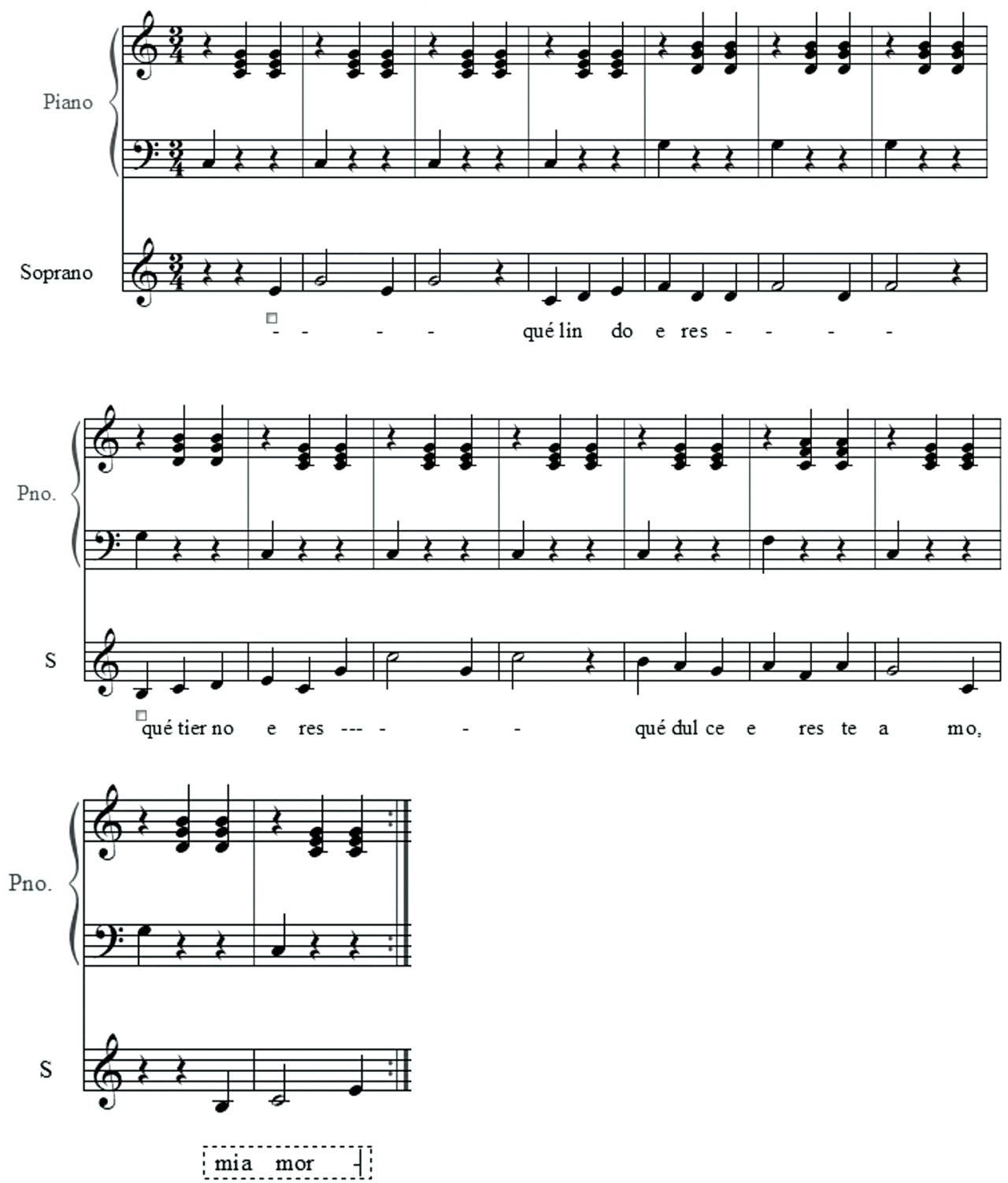

Fig. 1. Primera canción del método: Te amo, mi amor. 

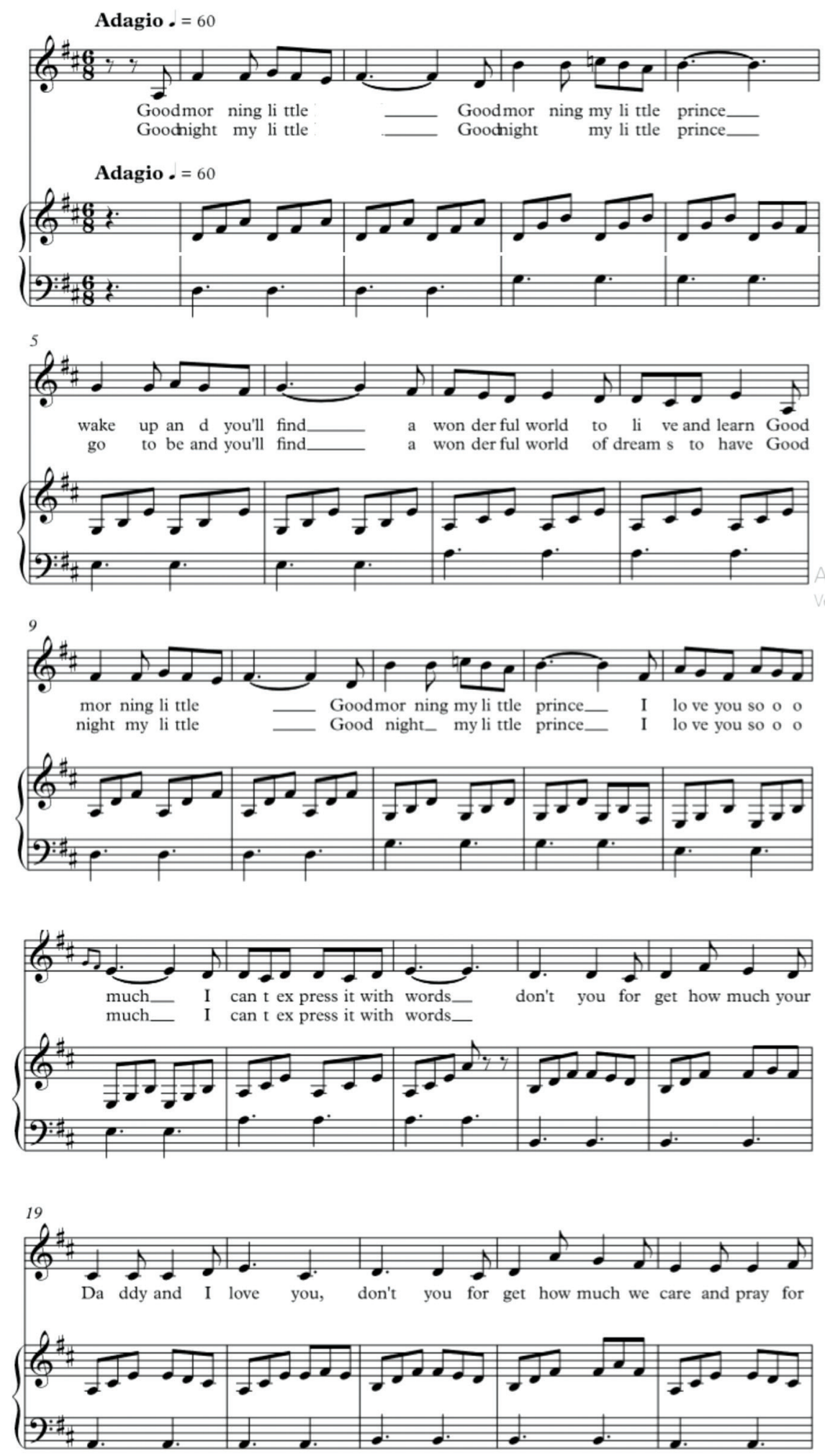

Fig. 2. Segunda canción del método musical de estimulación temprana: Good morning/Good night. 

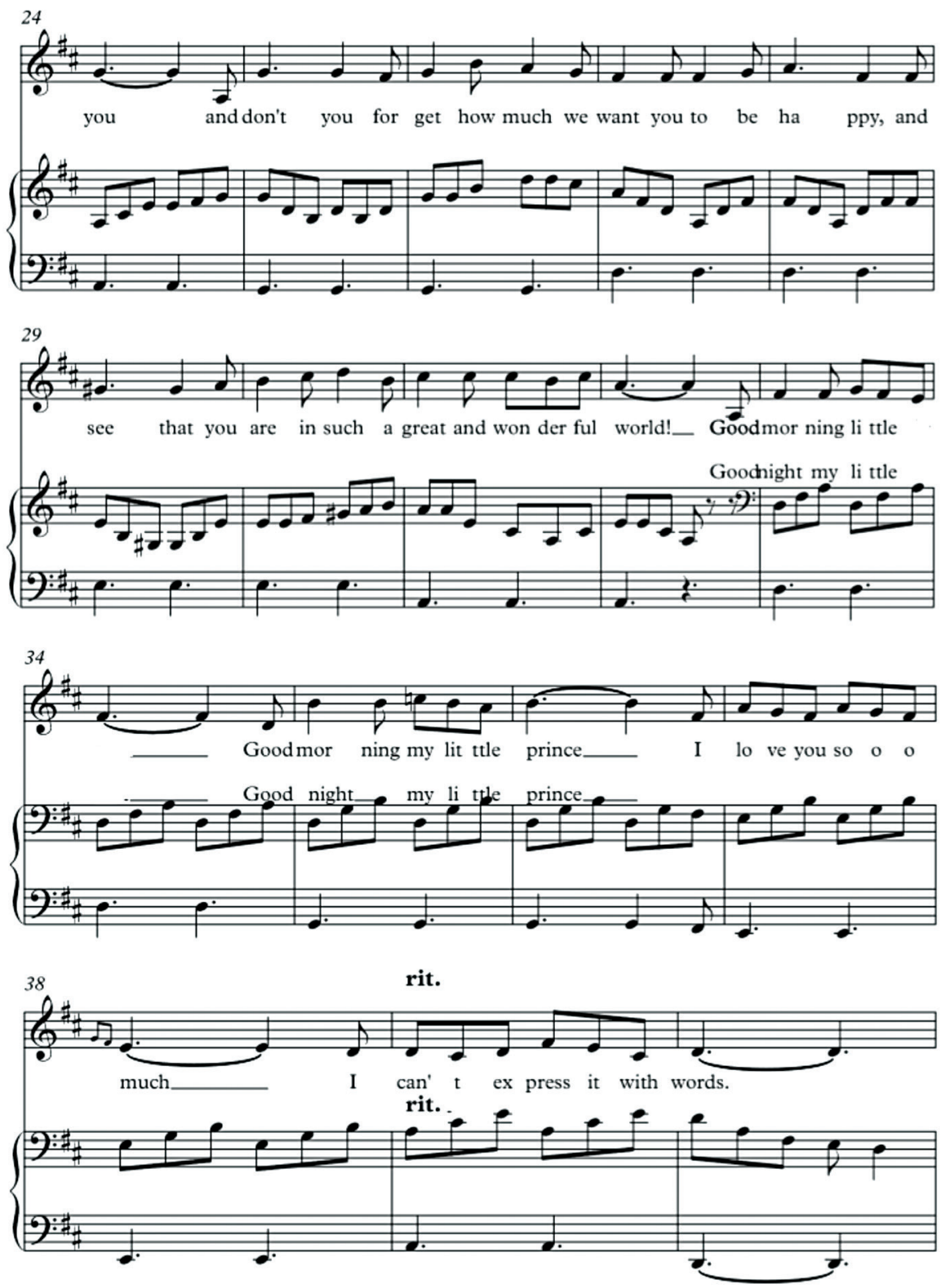

Fig. 2. (Continuación).

no poder decir con palabras el amor tan grande que se tiene por un hijo.

Así muchos padres la pueden aplicar y en los centros de cuido o estimulación, es excelente para un momento de relajación, para hacer la siesta, o para iniciar el día, según se quiera; con la ventaja además de que se puede aprender inglés si ese es el enfoque que se le quiere dar a la enseñanza.

La tercera canción del método de estimulación temprana es "Bollito de pan" (Fig. 3) está en particular es una de las preferidas de mis hijos, dado que surgió de un juego que le hacía a mi hijo mayor en la cama (que se puede replicar en una colchoneta, que esté a ras del suelo, sin obstáculos que puedan poner en peligro a los niños) y la dinámica es cantar la canción (o poner el disco) y hacerle "bollito de pan" al bebé.

Hacer "bollito de pan", consiste en acostar al bebé y darle vueltas como si fuera un rodillo para hacer pan, hacia la izquierda y hacia la derecha. Se le da una vuelta entera y a los niños les hará mucha gracia, mientras se les estimula el movimiento de "bollito de pan".

La cuarta canción es "Tortillitas" (Fig. 4) la cual se compuso con base en lo que muchas mamás hacen con sus hijos o con los de otros, al aplaudir y decir "tortillitas 

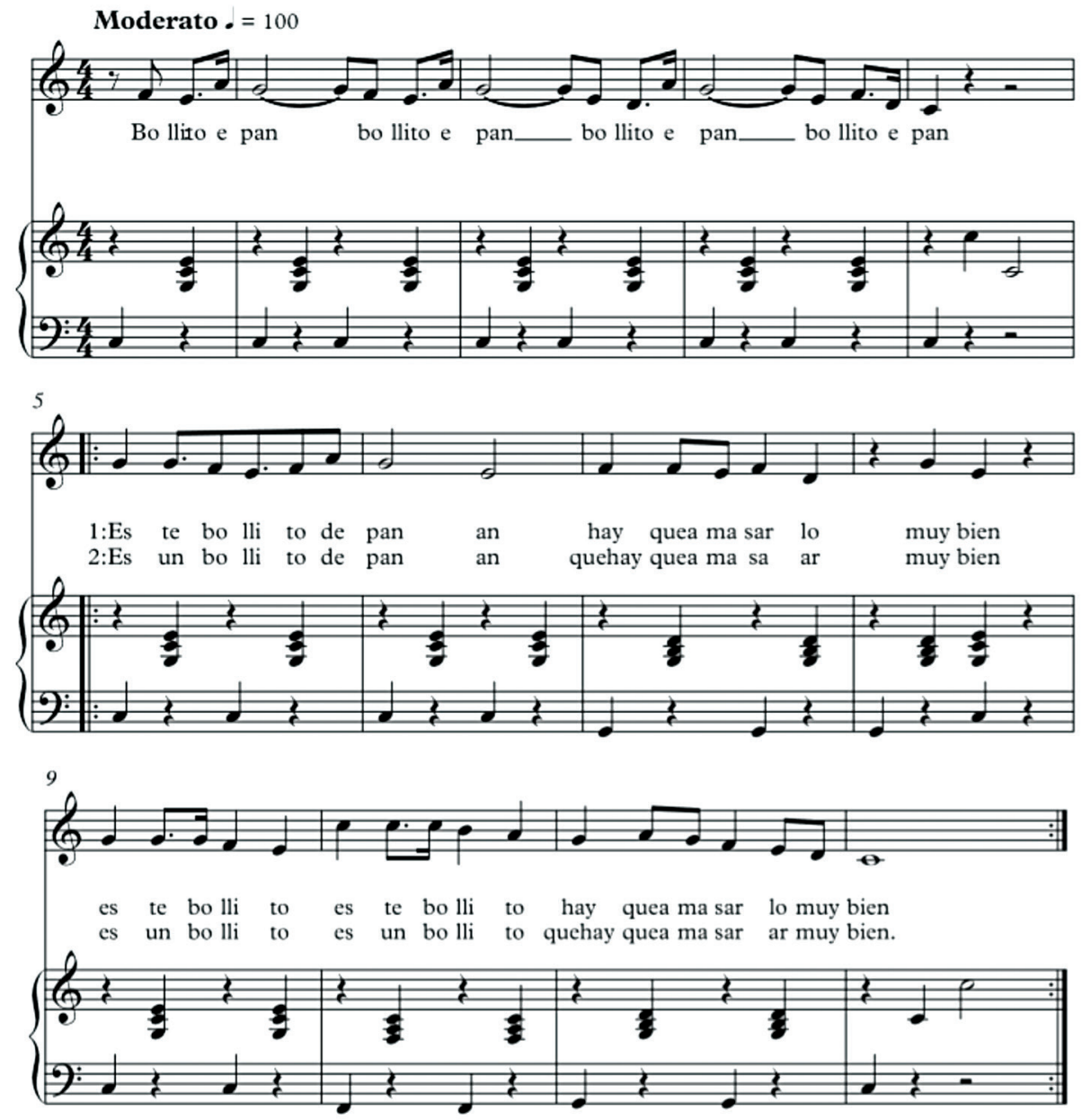

Fig. 3. Tercera canción del método musical de estimulación temprana: Bollito de pan.
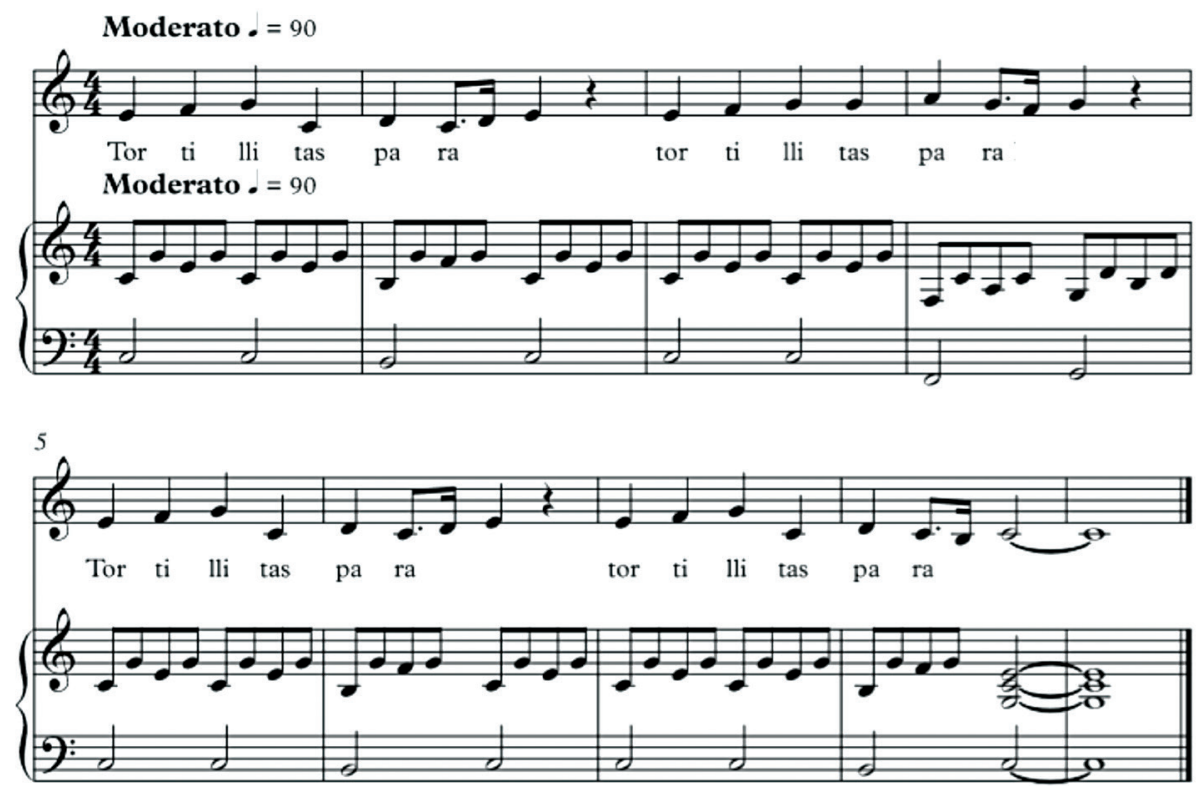

Fig. 4. Quinta canción del método musical de estimulación temprana:Tortillitas. 

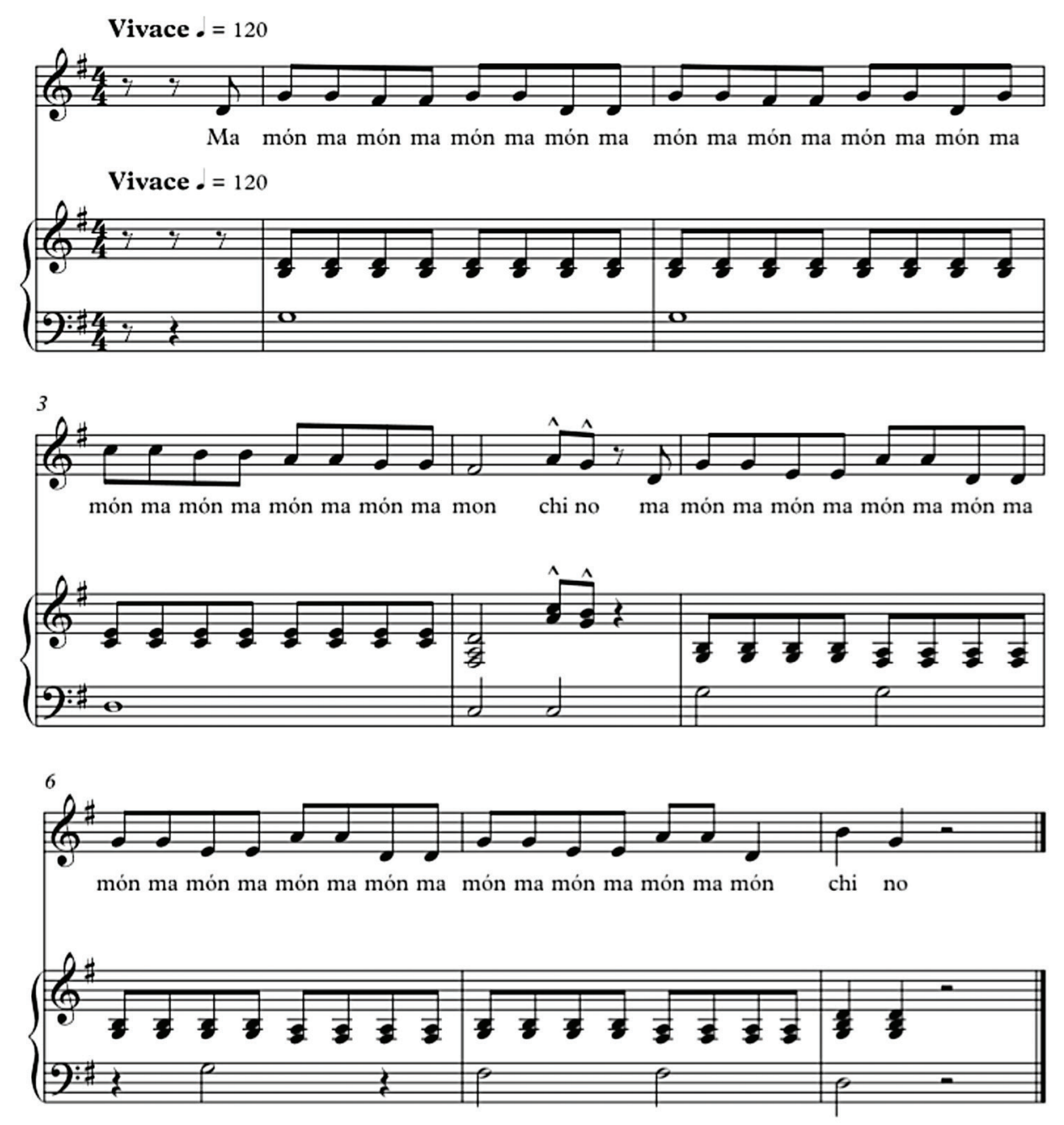

Fig. 5. Quinta canción del método musical de estimulación temprana: Mamón chino.

para..."y de ahí surgió la idea, dado que quería tener una cancioncita que pudiera cantarle a mis hijos, no sólo hacerlo hablado.

Esta canción tiene también un espacio en donde estaría el nombre de mi hijo, por lo que en lugar del espacio se puede decir el nombre de su alumno, su hijo, su nieto; entre otros.

La quinta canción del método es "Mamón chino" (Fig. 5) una canción muy divertida que lo que pretende es estimular el ritmo y al ser esta canción rápida, hace que la atención de los niños aumente. Se recomienda para iniciar la sesión es estimulación temprana, porque llama la atención de cualquiera y hace mucha gracia a los pequeños.

La sexta y última canción del método es "A E I O U" (Fig. 6) una manera de aprender las vocales de una manera temprana, y de aprender un poco de inglés. Si se ve la partitura, tiene las dos opciones: cantarla en español o cantarla mitad en español y mitad en inglés. Esto dependerá de si el grupo de niños que se tiene cuenta con edades diferentes, por lo que se podría dejar la opción que incluye inglés para niños más grandes, que aún puedan aprender las vocales. Además de pretender enseñar, es divertida y a los niños les encanta.

\section{DISCUSIÓN}

El amor infinito que se quiere transmitir en la canción "Te amo, mi amor", es importante que sea transmitido constantemente en los niños; especialmente, cuando están separados de sus padres en una guardería, red de cuido; más aún, en una clase de estimulación temprana; por ejemplo, es también relevante como para refuerzo de ese amor especial que mamá o papá tienen hacia él. 

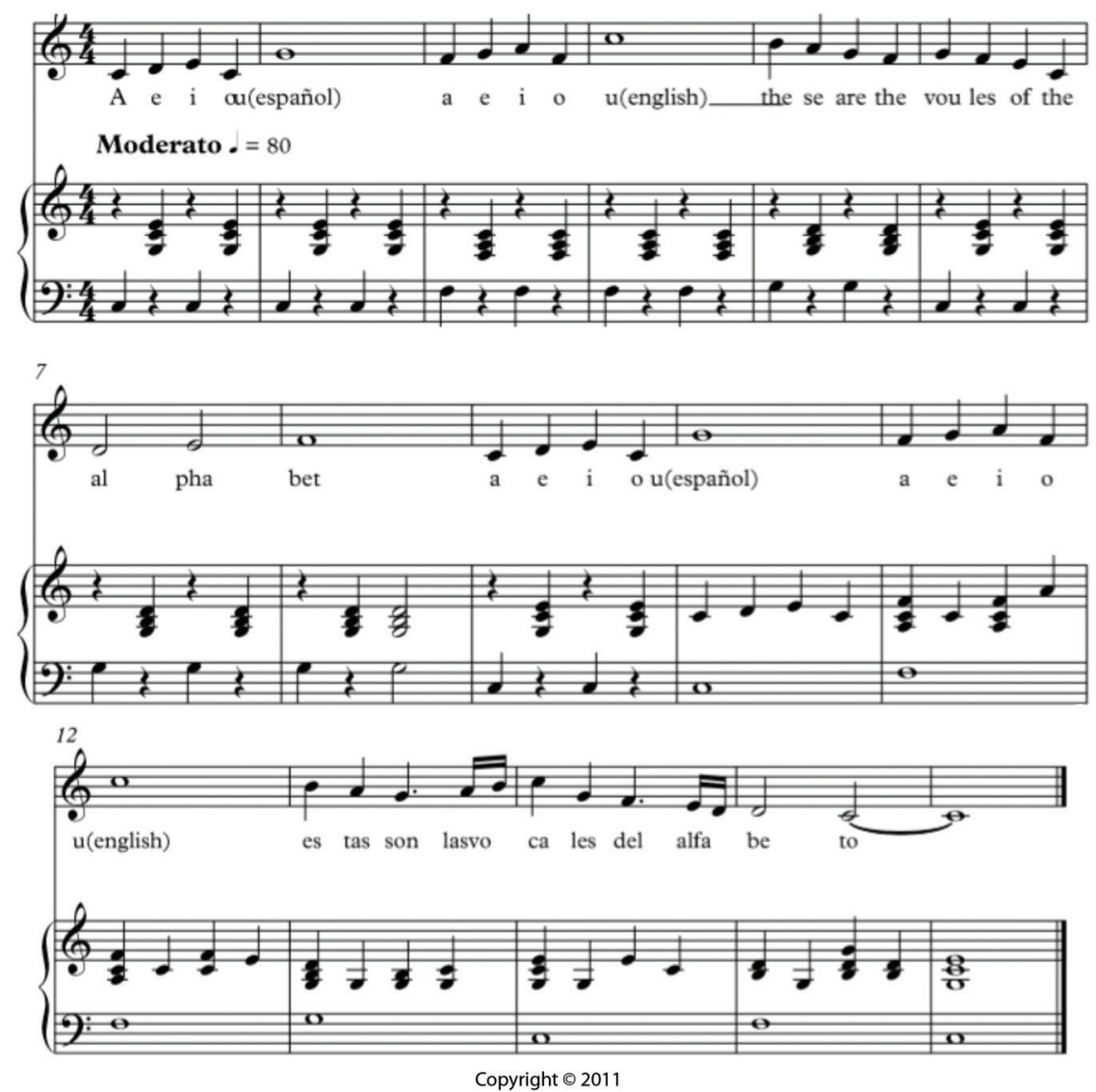

Fig. 6. Sexta canción del método musical de estimulación temprana: A E I O U.

Un estudio realizado por Sánchez (2018) encontró que existe una relación directa entre las familias que le dan estimulación temprana a sus hijos y el desarrollo afectivo que se desarrolla en ellos.

El tener una canción para despertar o dormir bien le transmite seguridad al bebé y es una canción que muchos niños recuerdan aún después de muchos años. Como anécdota, puedo dar fe de que mi hijo, cuando le canto la canción que le cantaba en el vientre, me dice "sí mami, sí me acuerdo" y ya han pasado muchos años. Eso es prueba del poder que tiene la música de transmitir seguridad y amor, porque eso es lo que mi hijo me expresa cuando reconoce su canción.

El buen dormir en los bebés no es fácil de conseguir, y muchos deben quedarse en guarderías hasta que sus papás pueden llegar a recogerlos muy tarde, por lo que es importante tener herramientas que les puedan transferir esa paz que necesitan para sentirse seguros a la hora de dormir. La música es una herramienta fundamental a nivel de preescolar cuando se trata de calmar a los niños y está comprobado que los hace sentir más seguros y tranquilos (Calderón, 2018, com. pers.).
En el siguiente peldaño del método se inicia con la expresión corporal, que desarrolla la motora gruesa tan importante en los bebés, a través de dos canciones que los hace mover todo el cuerpo, al convertirse en un bollito de pan o aprender a aplaudir. Fajardo, Pazmiño y Dávalos (2018) en un estudio que realizaron en un jardín de niños para determinar si la estimulación temprana asegura un óptimo desarrollo de los niños en su futuro; lograron demostrarlo, enfatizando en que el adulto es clave para lograr este avance en los niños. Otro estudio realizado por Herrera y Estefanía (2018) en donde se evaluaron las habilidades psicomotoras antes y después de haber implementado un programa de estimulación temprana, y se demostró que fue efectiva, al menos medianamente.

Seguidamente, la diversión no puede dejarse atrás, es primordial en los bebés para que se sientan felices y "Mamón chino" tiene ese efecto comprobado en mis hijos y los hijos de otros amigos a quienes se las he cantado. Lo importante es que, para utilizar esta canción, se realice en un momento en el que hay apertura para la diversión; por ejemplo, puede ser después del baño o después de una buena siesta. El sólo estimularle el oído 
al bebé con esta canción o las que escuchaba en el vientre, ayuda también al desarrollo del lenguaje y la comunicación según un estudio realizado por Pinango y Vega (2018) en donde evidenciaron que la estimulación temprana tiene un efecto positivo en este tema.

De igual manera, cuando se utilicen canciones para aprender inglés o las vocales, como "A E I O U", es importante también escoger bien el momento en el que se van a utilizar, para no tener contratiempos y sobre todo, enfatizar que estamos aprendiendo. De esta manera, se logrará una mayor concentración cuando inicien los estudios formales de preescolar y primaria y una visión más clara para diferenciar los momentos de ocio de los de obligación. Al respecto, en un estudio realizado por López (2018), en donde se compararon dos grupos, uno con estimulación cognitiva temprana y otro sin este tipo de estimulación y se encontró infantes con más seguridad, independencia y conexión social tanto en el contexto familiar como el colectivo. Por otro lado, Naser-Marco (2018), encontraron que el utilizar métodos multisensoriales para la enseñanza del inglés genera resultados positivos.

De igual manera, al introducir las canciones de manera paulatina y siguiendo el orden de dificultad que se ha establecido en este artículo, es como se obtendrán resultados más positivos y sanos para los bebés. Se recomienda aplicar este método a lo largo de todo un año, repitiendo las canciones al menos tres veces o más (si al niño le gustan), y siguiendo el orden establecido para después analizar los resultados a través de la prueba Denver II (Núñez, 2018), que se obtienen en un antes y un después y concluir sobre su utilidad. De igual forma, se recomienda aplicar la presente metodología en un grupo grande de niños, de diferentes edades en redes de cuido, guarderías o entidades públicas y privadas, para poder determinar su validez en grupos masivos.

La estimulación temprana en este estudio de caso específico generó efectos positivos en la muestra de niños en los que se probó, mejorando su autoestima, memoria y habilidades sociales, de lenguaje, cognitivas y de motora gruesa. Todo aprendizaje a nivel de estimulación temprana debe mantenerse como diversión y nunca verse como obligación, porque los resultados que se obtienen no son los mismos y más bien pueden ser contraproducentes.

\section{REFERENCIAS}

Arcos-Carhuamaca, W.G., \& Uscuchagua-Cornelio, M.A. (2017). Relación entre el sistema sensorial y el desarrollo del lenguaje oral en los estudiantes y docentes del primer grado del distrito de Yanacancha (Tesis de licenciatura). Facultad de Ciencias de la Educación, Universidad Nacional Daniel Alcides Carrión, Cerro de Pasco, Perú.

Aguilar-Cordero., M.J., Vieite-Ravelo., M., Padilla-López., C.A., Mur-Villar., N., Rizo-Baeza., M., \& Gómez-García., C.I. (2012). La estimulación prenatal: Resultados relevantes en el periparto. Nutrición Hospitalaria, 27(6), 2102-2108.

Benítez, M.A., Abrahan, V. M.D., \& Justel, N.R. (2017). Beneficios del entrenamiento musical en el desarrollo infantil: una revisión sistemática. Revista Internacional de Educación Musical, 5, 61-69. DOI: 10.12967/RIEM-2017-5-p061-069

Fajardo, Z.I.E., Pazmiño, M.I.A., \& Dávalos, Á.A.M. (2018). La estimulación temprana como factor fundamental en el desarrollo infantil. Espirales revista multidisciplinaria de investigación, 2(14), 25-36.

Flores, J. (2013). Efectividad del programa de estimulación temprana en el desarrollo psicomotor de niños de 0 a 3 años. Revista Ciencia y Tecnología, 9(4), 101-117.

Frega, A. (2005). Didáctica de la música: las enseñanzas musicales en perspectiva. Buenos Aires, Argentina: Bonum.

Jiménez, C. (2005). Inteligencia lúdica: juego y neuropedagogía en tiempos de transformación. Bogotá, Colombia: Magisterio.

Herrera, M., \& Estefanía, K. (2018). Implementación de un programa de estimulación temprana en niños y niñas de 0 a 3 años del centro infantil del buen vivir "Caritas Alegres" del cantón Ibarra de la provincia de Imbabura (tesis de bachillerato). Universidad Técnica del Norte, Imbabura, Ecuador.

López-Infante, Á.C. (2018). La cultura y el desarrollo socio afectivo en los niños de 4 a 5 años en el centro de salud Salasaca tipo by el centro de estimulación sembrando huellas (tesis de bachillerato). Universidad Técnica de Ambato, Ecuador.

Narváez-Montenegro, D. (2018). Las canciones infantiles y el desarrollo de la inteligencia lingüística de los niños de 4 a 5 años de la Unidad Educativa González Suárez (tesis de bachillerato). Universidad Técnica de Ambato, Ecuador.

Naser-Marco, N. (2018). El enfoque multisensorial en el aprendizaje del idioma inglés (tesis de bachillerato). Universidad Internacional de La Rioja, España.

Núñez-Ramírez, V. E. (2018). La estimulación temprana en el desarrollo integral en niños de 2 a 3 años (tesis de bachillerato). Universidad Técnica de Ambato, Ecuador.

Pinango, A., \& Vega, L. (2018). Estimulación auditiva como base para la adquisición y desarrollo del lenguaje. Revista Caribeña de Ciencias Sociales, abril, en línea. Recuperado de http://www.eumed.net/rev/caribe/2018/04/estimulacion-auditiva-lenguaje.html

Sánchez-Manosalva, N.J. (2018). Relación entre las prácticas familiares de estimulación temprana y el desarrollo afectivo en los niños y niñas de cinco años de la Institución Educativa del nivel inicial № 00958 del Caserío la Molina, distrito de Nueva Cajamarca en el año 2014 (Tesis de maestría). Universidad Nacional de San Martín, Perú. 